\title{
Phycocyanin from Spirulina platensis Induces Cytotoxicity and Apoptosis in T47D Cells
}

\author{
Safira Chairani Dimarti ${ }^{1 *}$, Neni Susilaningsih ${ }^{1,2}$, Renni Yuniati ${ }^{1,3}$ \\ ${ }^{1}$ Department of Biomedical Science, Faculty of Medicine, Universitas Diponegoro, Indonesia \\ ${ }^{2}$ Department of Anatomy and Histology, Faculty of Medicine, Universitas Diponegoro, Indonesia \\ ${ }^{3}$ Department of Dermatology and Venereology, Faculty of Medicine, Universitas Diponegoro, Indonesia \\ *Email: safirachairani@gmail.com
}

Submitted: 12 January 2020. Revised: 11 February 2020. Accepted: 20 March 2020

\begin{abstract}
Breast cancer cases in Indonesia have risen in alarming rate. Herbal medicines have been developed to complement conventional cancer therapy and to lessen the negative effects of the therapies. Phycocyanin, blue-green photosynthetic pigment from Spirulina platensis, becomes a potential candidate of herbal medicine for cancer therapy due to its capability to eliminate various cancer cell line on in vitro level. This research aimed to analyse the effectivity of phycocyanin to induce cytotoxic and apoptotic activity of T47D cells (breast cancer cell line). MTT assay was perform to measure $\mathrm{IC}_{50}$ value. Double-staining assay and flow cytometry were applied to visualize the appearance of apoptotic cells and to measure the percentage of apoptotic and necrotic cells. Result showed that the $\mathrm{IC}_{50}$ value of phycocyanin towards T47D cells is $1650 \mu \mathrm{g} / \mathrm{mL}$. Phycocyanin was also proven to induce apoptosis at $\mathrm{IC}_{50}$ with the apoptosis percentage of $45.93 \%$. This research presented different results from previous researches that used phycocyanin from saltwater Spirulina platensis. Based on the results of this study, phycocyanin has the potential to be developed as anticancer agent by inducing apoptosis.
\end{abstract}

Key words: Apoptosis; Cytotoxicity; Phycocyanin; Spirulina platensis; T47D

How to Cite: Dimarti, S. C., Susilaningsih, N., \& Yuniati, R. (2020). Phycocyanin from Spirulina platensis Induces Cytotoxicity and Apoptosis in T47D Cells. Biosaintifika: Journal of Biology \& Biology Education, 12 (1), 28-34

DOI: http://dx.doi.org/10.15294/biosaintifika.v12i1.22992

\section{INTRODUCTION}

Breast cancer has become one of the most common cases of cancer nowadays. In Indonesia, up to $21.4 \%$ of total cancer cases in women is occupied by breast cancer (World Health Organization, 2014). Various therapeutic methods have been developed to overcome the alarming rate of cancer cases in Indonesia. Currently-developed therapeutic methods work systematically by combining several pathways to eliminate cancer cells, such as induction of apoptosis, antiproliferation, and inhibition of normal cell mutation (Baig et al., 2016). Two of the most renowned modern conventional methods to cure cancer are chemotherapy and radiatiotherapy (Gotwals et al., 2017). Both chemotherapy and radiatiotherapy provide effective and rapid results. However, long-term exposure of these therapies also yields hazardous side effects for normal cells which lessen the quality of life of the patients. Several side effects that are posed by these therapies are nausea, vomiting, anorexia, decreased number of hemocytes, and hair-loss (Ohnishi \& Takeda, 2015). In order to reduce the dose of conventional therapy to minimize its side effects, herbal medicines are used as complementary therapy for cancer (Poonthananiwatkul et al., 2015).

Herbal medicines is popular for its safety and minimum side effects (Abd El-Hack et al., 2019).
This type of medicine is also known for its cancer elimination and immunomodulation properties. Spirulina platensis, an aquatic microalgae species, becomes one of the most promising candidates for herbal medicines. Spirulina platensis contains various photosynthetic pigments which have antioxidative properties (Agustini et al., 2015). One of the most prominent and dominant pigments in Spirulina platensis is phycocyanin.

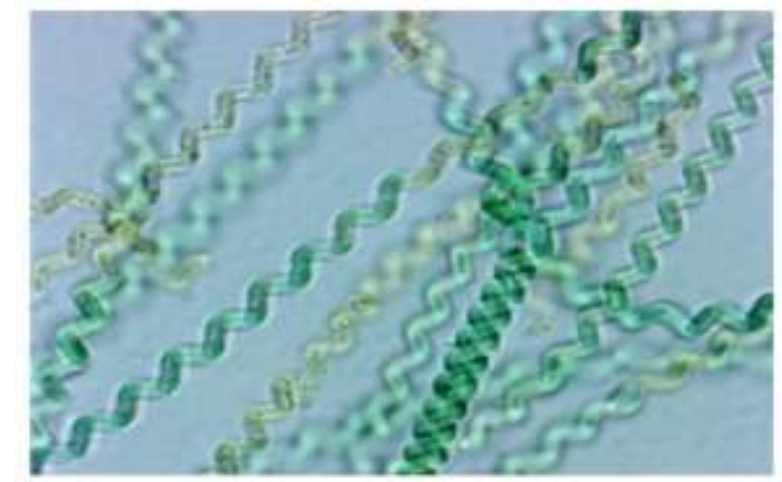

Figure 1. Spirulina platensis (Ramakrishnan, 2013).

Phycocyanin is a blue-green pigment in Spirulina platensis which has many beneficial properties, such as anticancer, antioxidant, and antiinflamatory agent (Yücetepe \& Özçelik, 2016). Scientific evidences for anticancer property of phycocyanin have been proven 
in several in vitro researches. Tumorigenic activity of various pancreatic cancer cell line, such as PANC-1 and Capan-1 can be inhibited by phycocyanin (Liao et al., 2016). Deniz et al. (2016) also reported the efficacy of phycocyanin in inhibiting the growth of lung cancer cell line, A549 cells. Phycocyanin is also known to trigger apoptosis with less toxic effects towards normal cells. Induction of apoptosis becomes a crucial point for a potential herbal anticancer agent due to its role to induce programmed cancer cell death that causes no inflammation (Hikam et al., 2019).

T47D becomes a decent breast cancer cell culture for in vitro research due to its high protein similarity to tumor and good response towards chemotherapy (Jiang et al., 2016). By such means, T47D is an ideal model for a research in determining the potential of a new or complimentary chemotherapeutic agent. However, the effectivity of phycocyanin to eliminate T47D cells (breast cancer cell line) had not been known before. Therefore, this research aimed to analyze the effectivity of phycocyanin to inhibit and eliminate T47D cells through the induction of cytotoxic and apoptotic activity. This research was expected to provide scientific information on the potential of herbal medicines, especially phycocyanin from freshwater Spirulina platensis, to be developed as an affordable anticancer agent.

\section{METHODS}

\section{Phycocyanin Sample}

Phycocyanin E18 from Spirulina platensis was purchased from Xi'an Surnature Biological Technology Co. Ltd. Spirulina platensis was cultured in freshwater ponds. Whole body of Spirulina platensis was used to obtain phycocyanin. After being harvested, phycocyanin was isolated from Spirulina platensis using spray drying method at the temperature of $160^{\circ}$ $180^{\circ}$ Celsius for three seconds. Solvent used in isolation process was water. Isolation process was continued with filtration, separation, and drying process. The output was blue phycocyanin E18 powder in 80 mesh size.

\section{Cytotoxicity Assay}

Cytotoxicity assay was performed using MTT assay in Laboratory of Parasitology, Faculty of Medicine Universitas Gadjah Mada. T47D cells were cultured in complete RPMI medium (RPMI $1640+$ Gib$\mathrm{co}^{\mathrm{TM}}$ fetal bovine serum + fungizone (Amphoterizine B) + Penicillin-Streptomycin) and incubated in 96well plate at the density of $1 \times 10^{4}$ cells $/ 100 \mu \mathrm{L} /$ well. Cells were incubated for 24 hours at $37^{\circ}$ Celsius and $5 \%$ of $\mathrm{CO}_{2}$. Concentration series (triplo) from phycocyanin was made by dissolving $10 \mathrm{mg}$ of phycocyanin powder with $100 \mu \mathrm{L}$ of dimethyl sulfoxide
(DMSO). Stock solution of phycocyanin was then diluted into $1000 ; 500 ; 250 ; 125 ; 62.5 ; 31.2 ; 15.6$; 7.8; 3.9 ; and $1.9 \mu \mathrm{g} / \mathrm{mL}$ for treatment. Positive control group was treated using $86 \mu \mathrm{g} / \mathrm{mL}$ of doxorubicin. Negative control was applied with only T47D cells with no treatment. The plate was incubated for 24 hours. Five $\mathrm{mg} / \mathrm{mL}$ of MTT was added into each well $(100 \mu \mathrm{L})$ after 24 hours. Plate was then incubated for 4 hours, then stopper solution (10\% of SDS dissolved in double-distilled water and $0.1 \mathrm{~N} \mathrm{HCl}$ ) was added into each well. Plate was then incubated overnight in room temperature. At the end of incubation time, cell viability was measured using ELISA reader at the absorbance $(\lambda)$ of $565 \mathrm{~nm}$. Cell viability was calculated using Microsoft Excel and analysed using The Quest Graph $\mathrm{IC}_{50}$ Calculator from AAT Bioquest.

\section{Double Staining Apoptosis Assay}

Sterile coverslips were inputted in each well of 24well plate. T47D cells were incubated at the density of $1 \times 10^{5}$ cells $/ 1000 \mu \mathrm{L} /$ well. Cells were incubated for 24 hours at $37^{\circ}$ Celsius and $5 \%$ of $\mathrm{CO}_{2}$. Cells were treated with phycocyanin at $\mathrm{IC}_{50}$, doxorubicin by 86 $\mu \mathrm{g} / \mathrm{mL}$, and complete medium, then they were incubated for 24 hours. At the end of incubation, coverslips were taken and put into object glass. Coverslips were stained using $10 \mu \mathrm{L}$ of Acridine Orange/Ethidium Bromide (AO/EB) stain. Samples were observed under fluorescence microscope. Viable cells appeared as green, while apoptotic/necrotic cells appeared as orange.

\section{Flow Cytometry Apoptosis Assay}

T47D cells were incubated in 6-well plate at the density of $5 \times 10^{5}$ cells/2000 $\mu \mathrm{L} /$ well. After 24 hours of initial incubation, cells were treated with phycocyanin $\left(\mathrm{IC}_{50}\right)$, doxorubicin $(86 \mu \mathrm{g} / \mathrm{mL})$, and complete medium (duplo). Plate was then incubated for another 24 hours. After incubation, cells from each well were harvested using $200 \mu \mathrm{L}$ of trypsin-EDTA and moved into conical tubes. Each tube was centrifuged at 3000 rpm for 3 minutes. Supernatant was resuspended. Suspension was put into eppendorf tubes. After centrifugation, each tube was covered in aluminium foil and added with ad $100 \mu \mathrm{L}$ of flow cytometry reagent $(100 \mu \mathrm{L}$ of PBS $+2 \mu \mathrm{L}$ of Annexin- $\mathrm{V}+2 \mu \mathrm{L}$ of propidium iodide). After 30 minutes of incubation, cell viability from each tube was measured using FACSCalibur flow cytometer. Analysis of apoptosis, necrosis, and cell viability was performed using CellQuest.

\section{RESULTS AND DISCUSSION}

Cytotoxic activity of phycocyanin was observed using MTT assay in 24 hours of incubation. The con- 
centration phycocyanin ranges from $1.9-1000 \mu \mathrm{g} / \mathrm{mL}$. Figure 2 demonstrates the viability of T47D cells treated with phycocyanin in gradual concentrations.

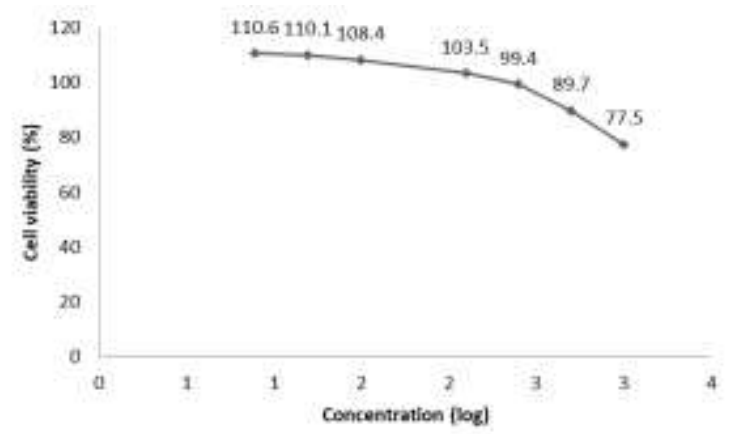

Figure 2. Viability percentage of T47D cells treated with phycocyanin on various concentration $(\mu \mathrm{g} / \mathrm{mL})$.

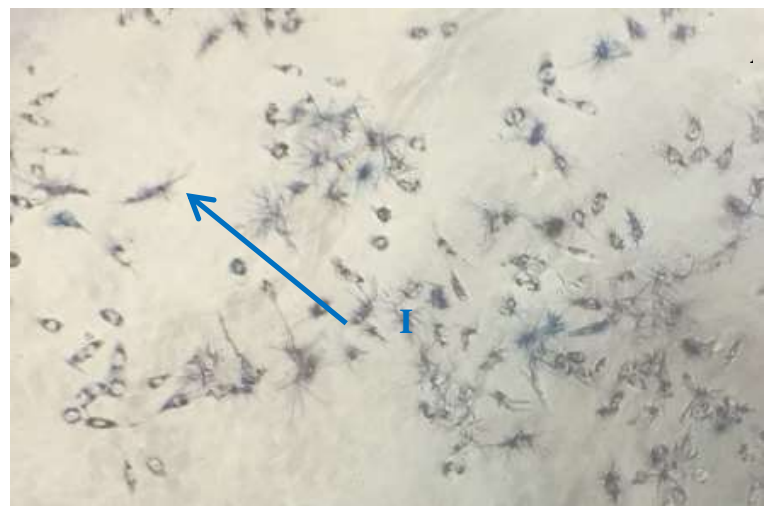

Results show that the viability of T47D cells decreases as the concentration of phycocyanin increases, indicating the decreasing trend of the cell viability (Figure 2). The viability reaches the lowest point in this research at the concentration of $1000 \mu \mathrm{g} / \mathrm{mL}$ with $77.476 \%$, whereas the highest cell viability is at the concentration of $7.8 \mu \mathrm{g} / \mathrm{mL}$ with $110.659 \%$, higher than the cells in negative control group. Based on calculation, the $\mathrm{IC}_{50}$ level of phycocyanin towards T47D cells in this research is $1650 \mu \mathrm{g} / \mathrm{mL}$. This result implies that at the highest concentration used in this research, the cell viability remains high. According to the cytotoxic classification reported by Weerapreeyakul et al. (2012), the substance is considered nontoxic towards T47D cells. Morphology of treated T47D cells following MTT assay were also observed through microscopic examinations.

Figure 3. Morphology of formazan crystals from T47D cells treated with (A) phycocyanin from Spirulina platensis at the concentration of $1000 \mu \mathrm{g} / \mathrm{mL}$ and (B) doxorubicin at the concentration of $86 \mu \mathrm{g} / \mathrm{mL}$ for 24 hours following MTT assay. I represents formazan crystals from living T47D cells, whereas II represents represents dead T47D cells (100x on inverted microscope).

Figure 3 demonstrates the morphological distinctions between positive control group and phycocyanin treatment group at the concentration of $1000 \mu \mathrm{g} / \mathrm{mL}$. Different treatment in each group poses different effect on the T47D cell morphology. Living T47D cells have cobblestone-like appearance that tightly adhere to other cells, forming a dense cellular bond. These living cells will react to MTT by generating formazan crystals as demonstrated by Figure 3A. Although not being tightly adhered to one another, majority of T47D cells survive following the phycocyanin treatment. Figure 3B shows the morphology of dead T47D cells. As the positive control group, doxorubicin is expected to induce cytotoxic activity in T47D cells that leads to cell death. As shown by Figure 3B, dead T47D cells shrink in size, changes into rounder shape, and become detached from another cells.

In-depth and focused visualization of living and dead T47D cells was obtained through double staining assay of the cells. T47D cells were stained with Acridine Orange/Ethidium Bromide (AO/EB) stain to emphasize the morphological distinctions between two conditions. Figure 4 represents the morphological conditions of T47D cells after being treated with phycocyanin at the concentration of $1650 \mu \mathrm{g} / \mathrm{mL}\left(\mathrm{IC}_{50}\right)$ and $3300 \mu \mathrm{g} / \mathrm{mL}\left(2 \mathrm{IC}_{50}\right)$.

Living cells are stained green and dead cells are stained as orange under fluorescence microscope. As shown in Figure 4A and 4B, there are considerable amount of living T47D cells. However, living T47D cells dominate the field of view. Living cells are also marked by an intact nucleus in the middle of the cell, as shown above. Dying cells has green-yellow color with fragmented nucleus. This condition implies that cells are nearing to death and will undergo another morphological alterations. Dying cells can only be found in Figure 4A. Dead cells are stained orange with visibly fragmented nucleus. These cells have more prominent nucleus alteration that marks cell death. As from the field of view, dead cells are more likely to be found in the concentration of 1650 $\mu \mathrm{g} / \mathrm{mL}$. Double staining assay is restricted to only visualize the cell conditions. The cause of the cell death cannot be determined from this assay. Furthermore, flow cytometry assay was employed to retrieve apoptosis percentage. 

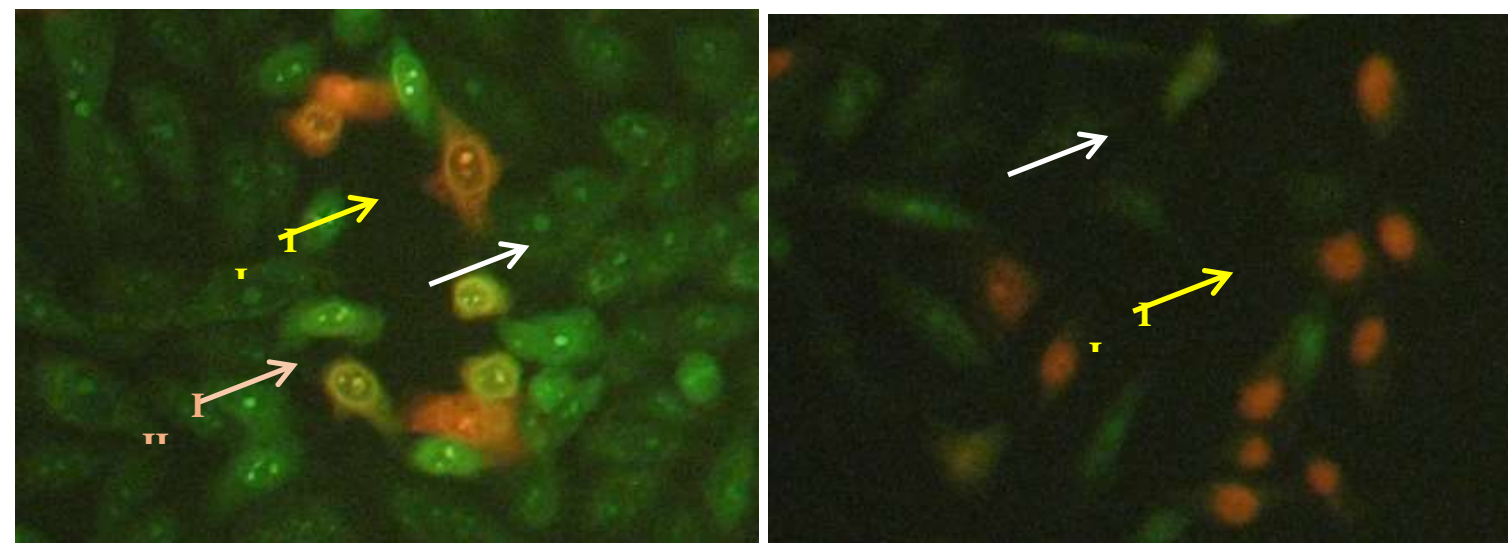

Figure 4. Morphology of T47D cells from double staining assay treated with (A) phycocyanin at $3300 \mu \mathrm{g} / \mathrm{mL}$ and (B) phycocyanin at $1650 \mu \mathrm{g} / \mathrm{mL}$ after 24 hours. I: living cells, II: dead cells, III: dying cells.
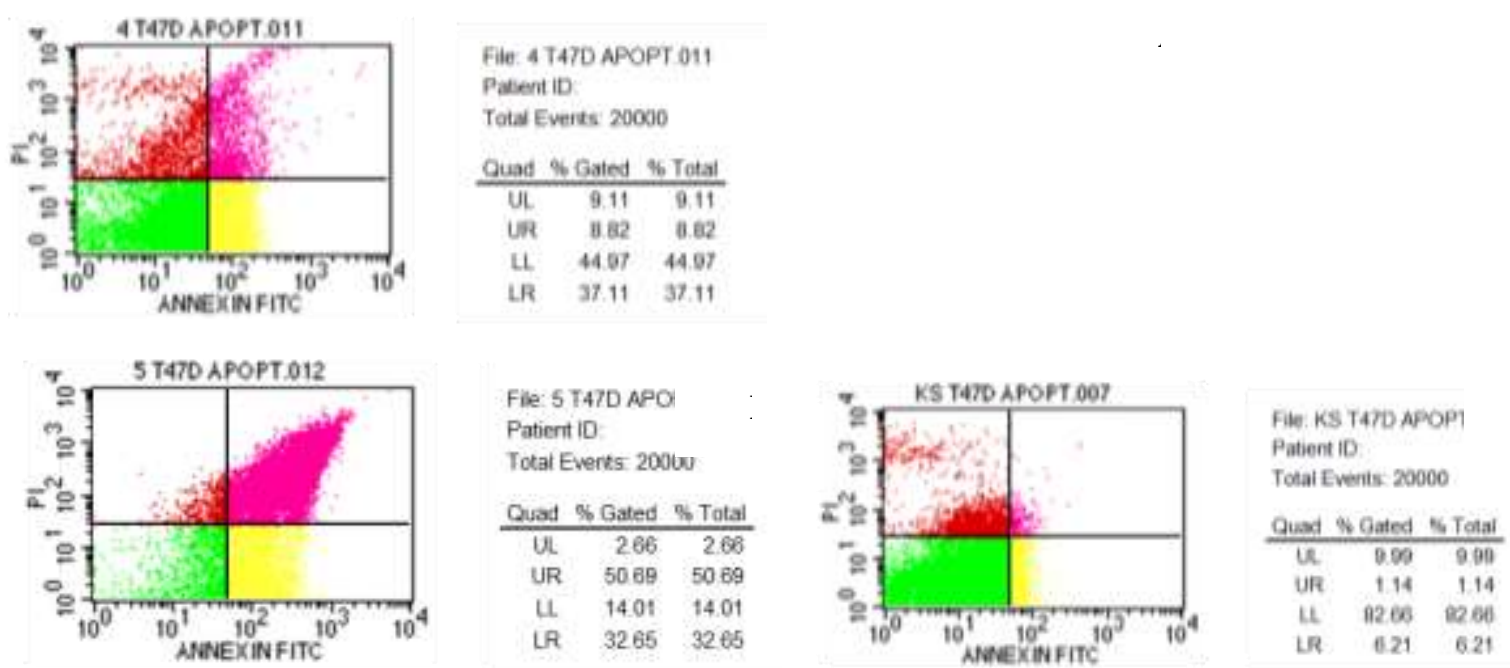

Figure 5. Percentage of apoptosis in T47D cells from the treatment of (A) phycocyanin at $1650 \mu \mathrm{g} / \mathrm{mL}$, (B) doxorubicin at $86 \mu \mathrm{g} / \mathrm{mL}$, and (C) complete medium as cell control group in flow cytometry assay after 24 hours of incubation.

Concentration of phycocyanin used in this assay was $1650 \mu \mathrm{g} / \mathrm{mL}$. Figure $5 \mathrm{~A}$ indicates that $45.93 \%$ of the total cell population underwent apoptosis.Based on Figure 5A, 55.03\% of the total undergoes cell death with $45.93 \%$ of it is induced by apoptosis. Most of the dead T47D cells are in early apoptotic stage and $9.11 \%$ of total cell population died due to necrosis. Doxorubicin as positive control reagent eliminates $83.34 \%$ of total cell population. According to Figure $4 \mathrm{~B}$, majority of the dead cells are in late apoptotic stage. As for cell control group, $82.66 \%$ of the total cells are alive and the rest $17.34 \%$ of total population is eliminated due to necrosis and apoptosis.

This research demonstrates the cytotoxic and apoptotic activity of phycoyanin towards T47D cells. Cytotoxicity represents the toxic level of a certain compound towards cells. It also determines whether the compound, especially natural compound, has the potential to become an effective anticancer agent. As shown in Figure 2, phycocyanin is considered nontoxic due to its high $\mathrm{IC}_{50}$ value. It implies that a large number of phycocyanin from Spirulina platensis is required to produce a potent herbal medicine as an anticancer agent. However, there is a decreasing viability trend in Figure 2 that could be referred as low toxicity, meaning that phycocyanin still has the potential to be developed as a herbal medicine for cancer. In this research, phycocyanin reduces T47D cell viability in dose-dependent manner. Further examinations, which were apoptotic assay using double staining and flow cytometry method were applied to prove the potential of phycocyanin as an anticancer agent.

Apoptosis becomes the targeted pathway for anticancer agents. One of the most prominent characteristics from cancer cells is the inability to undergo apoptosis or programmed cell death that will lead to infinite proliferation and immortality of the cells. Apoptosis is also important for cell death since it does not cause any inflammation that may lead to abrupt cell death, which is necrosis. Based on Figure 2 and Figure 3 , it is known that at the $\mathrm{IC}_{50}$ concentration, phycocyanin induces apoptosis. It also proves that alt- 
hough having low toxicity, phycocyanin still has the potential for further development as a natural anticancer agent due to its capability in inducing apoptosis in T47D cells.

Despite having high $\mathrm{IC}_{50}$ value, the overall results obtained from this research are aligned and consistent with previous researches that were conducted upon various cancer cell lines. According to Hao et al. (2018), phycocyanin is proven to inhibit cell cycle arrest in S phase in $\mathrm{H} 1299$ and $\mathrm{H} 460$ cell lines and in LTEP-A2 cell line, several types of non-small lung cancer cell lines. Possible mechanism that allegedly induces cell growth inhibition by phycocyanin is regulation of NF- $\kappa \beta$ pathway (Hao et al., 2018). It is also reported that phycocyanin activates caspase- 3 to partially induce apoptosis and blocks the growth of PANC-1, a pancreatic cancer cell line, in the transition of G0/G1 phase after 72 hours of treatment (Gao et al., 2016). Aside from the other type of cancer, phycocyanin is also known to induce cell death in another type of breast cancer cell line, such as MCF7 and MDA-MB-231. Despite coming from the same tissue type, these three cell lines possess different characteristics that distinguish them from one another. Phycocyanin induces apoptosis through intrinsic pathway in MDA-MB-231 and regulation Bcl-2/Bax ratio with $\mathrm{IC}_{50}$ value of $5.98 \pm 0,98 \mu \mathrm{M}$ (Ravi et al., 2015).

Low toxicity of phycocyanin is allegedly caused by the salinity of culture medium. In order to resolve the contamination and heavy metal accumulation issues in natural saltwater medium for Spirulina platensis cultivation, artificial saltwater and freshwater medium are developed (Liu et al., 2016). This research used phycocyanin that was obtained from freshwater-cultured Spirulina platensis. As reported by Mohan et al. (2014), Spirulina platensis grows in both saltwater and freshwater medium have high tolerance of salinity. However, different salinity level of medium also yields different phycocyanin content from the species. Liu \& Wu (2016) reported that Spirulina platensis produces higher phycocyanin content in artificial saltwater culture, which is Zarrouk medium with additional $200-400 \mathrm{mM}$ of $\mathrm{NaCl}$, compared to regular Zarrouk medium $(17 \mathrm{mM}$ of $\mathrm{NaCl})$. Similar result was also reported by Abdul-adel et al. (2019). Compared to freshwater-cultured Spirulina platensis, saltwater-cultured Spirulina platensis has higher phycocyanin/chlorophyll-a ratio (Ekantari et al., 2017). Saltwater medium is also proven to increase antioxidant capacity of Spirulina platensis. $\mathrm{NaCl}$ concentration in culture medium for Spirulina platensis directly correlates with salt stress. Spirulina platensis produces and accumulates osmotic substances and antioxidants, including phycocyanin, in high salinity medium to overcome cellular disruptions and damages that take place due to environmental stress. Photosynthetic pigments, including phycocyanin that are produced in this condition may be considered to provide protective measure for Spirulina platensis. Pigments also serve as antioxidants. However, excessive salt or salinity will significantly decrease phycocyanin content due to toxic ionic stress (Abdul-adel et al., 2019).

Cytotoxicity represents the potential of a certain substance to induce cell death. There are several probable mechanisms by phycocyanin that may induce cell death in cytotoxicity, including apoptosis. In this research, phycocyanin has been proven to induce apoptosis in T47D cells through flow cytometry assay. However, this research did not specify any mechanism or pathway that leads to apoptosis. In the other hand, there is no any specific elaboration on how phycocyanin eliminates T47D cells from previous researches. Generally, phycocyanin is known to stimulate the expression of proapoptotic genes, such as p21, p53 and Fas and to downregulate the expression of antiapoptotic genes, such as Bcl-2 (Silva et al., 2018). Phycocyanin can also induce apoptosis in cells through cascade mechanisms. By altering the mitochondrial membrane permeabilization (MMP), phycocyanin induces the release of cytochrome-c that catalyse the apoptosis through intrinsic pathway. Phycocyanin is also known to upregulate caspase- 3 protein that accounts for apoptosis (Jiang et al., 2017). In a more specific manner, there are specified mechanisms that take place after phycocyanin treatment upon several types of breast cancer cell lines, such as MDA-MB-231 (Jiang et al., 2018). Ravi et al. (2015) reported that phycocyanin simultaneously upregulates caspase- 9 and alters the $\mathrm{Bcl}-2 / \mathrm{Bax}$ ratio that induce apoptosis. Reduction of ERK1/2 phosphorylation is also observed following phycocyanin treatment in MDA-MB-231, which shifts the progression from cellular survival to apoptosis. Besides that, phycocyanin also induces apoptosis in MDA-MB-231 through mitogen-activated protein kinase (MAPK) pathway, specifically by upregulating and activating p38 MAPK (Jiang et al., 2018). Another mechanism correlates directly to the downregulation of CDK2 and cyclin $\mathrm{E}$, a protein that is held accountable for cell cycle progression. By inhibiting cell cycle progression, existing cancer cells are expected to withhold the proliferation and later will be directed to undergo the apoptotic death. Human matrix metalloproteinase (MMP), especially MMP-2 and MMP-9, are also regulated by phycocyanin to ensure the sustainability of homeostatic condition and prevent cancer growth (Kunte \& Desai, 2017).

Generally, this research serves different result of cytotoxic and apoptotic induction due to different source of Spirulina platensis for phycocyanin. Most 
of previous researches used Spirulina platensis from saltwater culture, while this research utilized freshwater-cultured Spirulina platensis as the source of phycocyanin. This research serves to provide an insight in the anticancer potential of phycocyanin from freshwater-cultured Spirulina platensis. Eventhough phycocyanin is proven to be nontoxic towards T47D cells, further developments may be conducted to improve the anticancer activity of phycocyanin. As both phycocyanin and Spirulina platensis have been widely consumed, this research is expected to provide scientific informations for people in general about the anticancer potential of both ingredients. Although this research has demonstrated the cytotoxic and apoptotic effect of phycocyanin from freshwater Spirulina platensis upon T47D cells, a larger amount of replication and more profound insight in possible mechanisms needs to be carried out. It is required to determine further steps to enhance the potential of phycocyanin as an anticancer agent. Sufficient amount of replication and enhancement methods will also provide more profound scientific informations on how phycocyanin affect breast cancer cells that is beneficial for community in general.

\section{CONCLUSION}

$\mathrm{IC}_{50}$ value of phycocyanin towards $\mathrm{T} 47 \mathrm{D}$ cells is $1650 \mu \mathrm{g} / \mathrm{mL}$ and is considered nontoxic. However, phycocyanin from Spirulina platensis is proven to induce apoptotic activity at the $\mathrm{IC}_{50}$ concentration. Most of the dead cells are in early apoptotic stage. It is concluded that phycocyanin has the potential to be developed as an anticancer agent. Further enhancement is required to increase phycocyanin toxicity due to its potential in eliminating cancer cells.

\section{ACKNOWLEDGEMENT}

We convey our deepest gratitude for Ajeng Kurniasari Putri, M.Biomed. and the staff of Laboratory of Parasitology, Faculty of Medicine, Universitas Gadjah Mada for providing cell culture training and utilities for this research.

\section{REFERENCES}

Abd El-Hack, M. E., Abdelnour, S., Alagawany, M., Abdo, M., Sakr, M. A., Khafaga, A. F., Mahgoub, S. A., Elnesr, S. S., \& Gebriel, M. G. (2019). Microalgae in modern cancer therapy: Current knowledge. Biomedicine and Pharmacotherapy, 111(October 2018), 42-50.

Abdul-adel, E., Saleh, M. M., \& Salman, J. M. (2019). Production of phyotosynthesis pigments by Spirulina platensis under different $\mathrm{NaCl}$ concentrations. Plant Archives, 19(2), 3254-3258.

Agustini, T. W., Suzery, M., Sutrisnanto, D., Ma'ruf, W. F., \& Hadiyanto. (2015). Comparative Study of Bioactive Substances Extracted from Fresh and Dried Spirulina sp. Procedia Environmental Sciences, 23(Ictcred 2014), 282-289.

Baig, S., Seevasant, I., Mohamad, J., Mukheem, A., Huri, H. Z., \& Kamarul, T. (2016). Potential of apoptotic pathway-targeted cancer therapeutic research: Where do we stand. Cell Death and Disease, 7(1), e2058.

Deniz, I., Ozen, M. O., \& Yesil-Celiktas, O. (2016). Supercritical fluid extraction of phycocyanin and investigation of cytotoxicity on human lung cancer cells. Journal of Supercritical Fluids, 108, 13-18.

Ekantari, N., Marsono, Y., Pranoto, Y., \& Harmayani, E. (2017). Pengaruh Media Budidaya Menggunakan Air Laut dan Air Tawar terhadap Sifat Kimia dan Fungsional Biomassa Kering (Spirulina platensis). Agritech, 37(2), 173.

Gao, B., Yang, X., Cheng, X., Gao, Y., Liao, G., \& Ou, Y. (2016). Phycocyanin Inhibits Tumorigenic Potential of Pancreatic Cancer Cells: Role of Apoptosis and Autophagy. Scientific Reports, 6(1), $1-12$.

Gotwals, P., Cameron, S., Cipolletta, D., Cremasco, V., Crystal, A., Hewes, B., Mueller, B., Quaratino, S., Sabatos-Peyton, C., Petruzzelli, L., Engelman, J. A., \& Dranoff, G. (2017). Prospects for combining targeted and conventional cancer therapy with immunotherapy. Nature Reviews Cancer, 17(5), 286-301.

Hao, S., Yan, Y., Li, S., Zhao, L., Zhang, C., Liu, L., $\&$ Wang, C. (2018). The in vitro anti-tumor activity of phycocyanin against non-small cell lung cancer cells. Marine Drugs, 16(6), 1-15.

Hikam, A. R., Ekowati, N., \& Hernayanti. (2019). The cytotoxic and apoptosis effects of chloroform extracts of Auricularia auricula on cervical cancer cells. Biosaintifika, 11(63), 32-38.

Jiang, G., Zhang, S., Yazdanparast, A., Li, M., Pawar, A. V., Liu, Y., Inavolu, S. M., \& Cheng, L. (2016). Comprehensive comparison of molecular portraits between cell lines and tumors in breast cancer. BMC Genomics, 17(525), 281-301. z

Jiang, L., Wang, Y., Liu, G., Liu, H., Zhu, F., Ji, H., \& Li, B. (2018). C-Phycocyanin exerts anti-cancer effects via the MAPK signaling pathway in MDAMB-231 cells. Cancer Cell International, 18(1), 1-14. https://doi.org/10.1186/s12935-018-0511-5

Jiang, L., Wang, Y., Yin, Q., Liu, G., Liu, H., Huang, Y., \& Li, B. (2017). Phycocyanin: A potential drug for cancer treatment. Journal of Cancer, 8(17), 3416-3429. 
Kunte, M., \& Desai, K. (2017). The Inhibitory Effect of C-phycocyanin Containing Protein Extract (CPC Extract) on Human Matrix Metalloproteinases (MMP-2 and MMP-9) in Hepatocellular Cancer Cell Line (HepG2). Protein Journal, 36(3), 186195.

Liao, G., Gao, B., Gao, Y., Yang, X., Cheng, X., \& Ou, Y. (2016). Phycocyanin Inhibits Tumorigenic Potential of Pancreatic Cancer Cells: Role of Apoptosis and Autophagy. Scientific Reports, 6(1), $1-12$.

Liu, C., Li, L.-J., Wu, C.-Y., Guo, K.-N., \& Li, J.-H. (2016). Growth and antioxidant production of Spirulina in different $\mathrm{NaCl}$ concentrations. Biotechnology Letters, 38(7), 1089-1096.

Mohan, A., Misra, N., Srivastav, D., Umapathy, D., \& Kumar, S. (2014). Spirulina- The Nature' $s$ Wonder : A Review. 2, 1334-1339.

Ohnishi, S., \& Takeda, H. (2015). Herbal medicines for the treatment of cancer chemotherapy-induced side effects. Frontiers in Pharmacology, 6(FEB), $1-5$.

Poonthananiwatkul, B., Howard, R. L., Williamson, E. M., \& Lim, R. H. M. (2015). Cancer patients taking herbal medicines: A review of clinical purposes, associated factors, and perceptions of benefit or harm. Journal of Ethnopharmacology, 175, $58-66$.
Ramakrishnan, R. (2013). Anticancer properties of blue green algae Spirulina platensis - Review. International Journal of Medicine and Pharmaceutical Sciences (IJMPS), 3(4), 159-168.

Ravi, M., Tentu, S., Baskar, G., Rohan Prasad, S., Raghavan, S., Jayaprakash, P., Jeyakanthan, J., Rayala, S. K., \& Venkatraman, G. (2015). Molecular mechanism of anti-cancer activity of phycocyanin in triple-negative breast cancer cells. BMC Cancer, 15(1), 1-13.

Silva, E. F. e, Figueira, F. da S., Lettnin, A. P., Carrett-Dias, M., Filgueira, D. de M. V. B., Kalil, S., Trindade, G. S., \& Votto, A. P. de S. (2018). CPhycocyanin: Cellular targets, mechanisms of action and multi drug resistance in cancer. Pharmacological Reports, 70(1), 75-80.

Weerapreeyakul, N., Nonpunya, A., Barusrux, S., Thitimetharoch, T., \& Sripanidkulchai, B. (2012). Evaluation of the anticancer potential of six herbs against a hepatoma cell line. Chinese Medicine, 7(15), 1-7.

World Health Organization. (2014). Cancer Country Profile: Indonesia. In Cancer Country Profiles.

Yücetepe, A., \& Özçelik, B. (2016). Bioactive Peptides Isolated from Microalgae Spirulina platensis and their Biofunctional Activities. Akademik Gida, 14(4), 412-417. 